\title{
Perceived learning environment and students' emotional experiences: A multilevel analysis of mathematics classrooms ${ }^{\text {is }}$
}

\author{
Anne C. Frenzel*, Reinhard Pekrun, Thomas Goetz ${ }^{1}$ \\ University of Munich, Department of Psychology, Leopoldstraße 13, 80802 Munich, Germany
}

\begin{abstract}
A multilevel approach was used to analyse relationships between perceived classroom environments and emotions in mathematics. Based on Pekrun's (2000) [A social-cognitive, control-value theory of achievement emotions. In J. Heckhausen (Ed.), Motivational psychology of human development (pp. 143 163)] social-cognitive, control-value theory of achievement emotions, we hypothesized that environmental characteristics conveying control and value to the students would be related to their experience of enjoyment, anxiety, anger, and boredom in mathematics. Multilevel modelling of data from 1623 students from 69 classes (grades 5 10) confirmed close relationships between environmental variables and emotional experiences that functioned predominantly at the individual level. Compositional effects further revealed that classes' aggregate environment perceptions as well as their compositions in terms of aggregate achievement and gender ratio were additionally linked to students' emotions in mathematics. Methodological and practical implications of the findings are discussed.
\end{abstract}

Keywords: Enjoyment; Anxiety; Anger; Boredom; Mathematics; Learning environment; Multilevel modelling

The classroom learning environment embodies more than merely physical space, indeed it consists of the entire learning setting, including instructional processes, teacher-student relationships, student-student relationships and student attitudes (e.g., Brophy, 1999; Fraser \& Walberg, 1991; Moos, 1979). Learning environments can be conceptualised in terms of observable characteristics, such as school buildings, materials used for instruction, and externally observed interactions between and among learners and instructors. Alternatively, learning environments can be conceptualised as the teachers' or students' subjective perceptions of their learning setting. The latter approach has proved very fruitful, subjectively perceived environments having been associated with a range of important outcomes for students. Numerous studies have clearly demonstrated that the perceived learning environment is significantly related to student achievement (Fraser, 1994; McRobbie \& Fraser, 1993; Moos, 1979), as well as emotional and social outcomes (Anderman, 2002; Anderman, Eccles, Yoon, Roeser, Wigfield, \& Blumenfeld, 2001; Fraser, 1994; Turner et al., 2002).

\footnotetext{
This research was supported by a grant from the Deutsche Forschungsgemeinschaft (German Research Foundation, PE 320/11 2) awarded to the second author.

* Corresponding author. Tel.: +49 892180 6047; fax: +49 8921805250

E mail addresses: frenzel@edupsy.uni muenchen.de (A.C. Frenzel), pekrun@edupsy.uni muenchen.de (R. Pekrun), thomas.goetz@ uni konstanz.de (T. Goetz).

${ }^{1}$ University of Konstanz, Germany and College of Teacher Education Thurgau, Switzerland.
} 
The present study aimed to analyse how students' perceptions of the classroom environment relate to their emotional experiences in mathematics. It can be assumed that students experience a wide range of emotions in the context of learning and achievement. Yet, with the exception of test anxiety (e.g., Zeidner, 1998) and Weiner's research on attributional antecedents of achievement-related emotions (e.g., Weiner, 1986), educational research has paid comparatively little regard to emotions, in particular to positive emotions (see Pekrun, Goetz, Titz, \& Perry, 2002a). This also applies to research in the domain of mathematics. Excepting the well-researched area of mathematics anxiety (e.g. Fennema \& Sherman, 1976; Wigfield \& Meece, 1988), we currently lack empirical evidence concerning students' emotions in connection with learning and achievement in mathematics. Thus, little is known about the relationships between students' perceptions of their classroom environment and their emotional experiences in mathematics. However, even beyond achievement, students' emotional experiences can be considered as relevant outcome variables in themselves, constituting important factors of student well-being (e.g., Goetz, Zirngibl, \& Pekrun, 2003; Salovey, Rothman, Detweiler \& Steward, 2000).

In the present study, we chose to more closely examine enjoyment, anxiety, anger, and boredom as experienced in mathematics. These four emotions were selected for investigation on the basis of two major reasons. First, we wanted to analyse those emotions most frequently occurring in the context of learning and achievement. In exploratory interview studies, enjoyment and anxiety were reported as the most commonly experienced achievement-related emotions by middle school, high school and university students, with anger and boredom also being reported as occurring fairly frequently (Pekrun, Goetz, Titz, \& Perry, 2002b; Titz, 2001). Employing an experience sampling method to explore the prevalence of boredom at school, Larson and Richards (1991) showed that middle school students were on average bored for $32 \%$ of the total time in which they attended classes. Second, in choosing these four emotions we strived to cover achievement emotions with different foci, including both outcome-related and activity-related emotions. Enjoyment comprises both concurrent, activity-related aspects (e.g., enjoyment of learning) and outcome-related aspects (e.g., joy regarding success). Boredom pertains to ongoing activities (boredom while attending lessons), whereas anxiety and anger are usually experienced as outcome-directed emotions (fear of failure or anger at failure). We considered outcome-related emotions and activity-related emotions to be differentially linked to facets of the environment (see below). The present study therefore seeked to include a well-balanced combination of activity- and outcomerelated academic emotions.

\section{The impact of perceived classroom environment on students' emotional experiences: empirical findings}

Achievement has been the number-one variable considered as an outcome of perceived classroom environment. Numerous studies have clearly demonstrated that the perceived learning environment is significantly related to student achievement (Fraser, 1994; McRobbie \& Fraser, 1993). Comparatively little is known about affective correlates of perceived classroom environment. The few existing studies addressing emotions in relation to perceived classroom environments mostly concentrate on anxiety, with other emotions having received relatively sparse attention.

In a meta-analysis of the causes, correlates and effects of test anxiety, Hembree (1988) incorporated 10 studies analysing relationships between students' teacher perceptions and test anxiety. Hembree summarized that while individual student perceptions of the teacher as negative and unfriendly were moderately correlated to test anxiety $(r=0.16)$, positive and friendly teacher perceptions showed no significant relationship to individual levels of test anxiety. Pekrun (1992) reported, from both cross-sectional and longitudinal analyses, that individual levels of test anxiety were positively related to individually perceived achievement-related pressure and punishment from teachers as well as to individual perceptions of competition among classmates across grade levels 5-10. Using the class as the unit of analysis and controlling for important class characteristics (e.g., school type, age, proportion of boys in the class), Helmke (1983) also reported positive correlations between anxiety on one hand and perceived punitive teacher behaviour, pressure for achievement and perceived competition among classmates on the other.

With regard to studies addressing achievement emotions beyond anxiety, it is worth mentioning studies by Jacob (1996) and Goetz, Pekrun, Hall, and Haag (2006). Jacob (1996) investigated relationships between perceived classroom environment variables and middle- and high school students' test-related emotions including enjoyment, anxiety, anger, hopelessness and shame. Perceived teacher enthusiasm and supportive achievement-contingent feedback from the teacher (e.g., praise for success, support after failure) were positively related to individual levels of academic enjoyment (correlations between $r=0.35$ and $r=0.39$ ). In addition, perceived failure-contingent teacher punishment positively correlated with anger, hopelessness, shame, and anxiety (Pearson's $r$ between 0.19 and 0.38 ). Finally, Jacob 
reported that perceived competition among classmates positively correlated with both anxiety and enjoyment. Goetz et al. (2006) examined student perceptions of their learning environment and emotions experienced within the subject of Latin. In their study, individually perceived positive reinforcement of achievement, teacher enthusiasm, and elaborative instruction in Latin were positively related to individual reports of enjoyment and pride, and negatively related to individual reports of anger and boredom. Achievement pressure from the teacher, however, proved to be positively related to student anxiety and anger, and negatively related to enjoyment and pride in Latin.

Furthermore, in a study on affective and cognitive outcomes of the perceptions of classroom environment variables, Fraser and Fisher (1982) found positive correlations between a class' mean perceptions of participation, involvement, affiliation, task orientation, order and organization, and rule clarity as measured with the "Individualised Classroom Environment Questionnaire" (ICEQ) and the "Classroom Environment Scale" (CES) on the one hand, and the students' average enjoyment of science lessons on the other. With the class as the unit of analysis and corresponding pre-test and general ability controlled for, they reported partial correlations between perceptions of these facets of science lessons and enjoyment ranging between 0.20 and 0.36 .

In summary, these scattered empirical findings provide consistent support of a positive relationship between anxiety and perceived punishment from the teacher as well as competition among classmates. Perceived characteristics of teacher instructional strategies (e.g., quality of instruction and achievement-contingent feedback) as well as peer engagement would appear to be important positive correlates of academic enjoyment.

\section{A control-value theoretical approach to the impact of perceived classroom environment on emotions}

Our assumption that students' emotional experiences are related to their perceptions of the classroom environment is derived from the empirical data presented above and based on Pekrun's $(1992,2000)$ social-cognitive, control-value theory of academic emotions. This theory postulates that a student's environment (including parents, teachers, and peers) influences his or her achievement-related appraisals of control and value, which in turn are posited to be antecedents of emotional experiences. Achievement-related control appraisals include judgments of competence, causal expectancies, and causal attributions for success and failure. Achievement-related value appraisals comprise perceptions of the importance of achievement-related actions, which we term action values (i.e., the value inherent to the respective activity, e.g., dealing with figures in mathematics). In addition, value appraisals include the subjective value of achievement outcomes, which we refer to as achievement outcome values (i.e., the perceived importance of attaining success and avoiding failure in mathematics). The theory holds that control appraisals are important for both activity- and outcome-related emotions. Action values are assumed to be significant for activity-related emotions, and outcome values for outcome-related emotions. Consequently, enjoyment, being both activity-related and outcome-related, should result from high control appraisals and high subjective activity- and outcome-values. Anxiety, as an outcome-related emotion, should result from low control appraisals, paired with high achievement outcome values. Outcome-related anger would be expected to result from low internal (and high external) control appraisals, along with high achievement outcome values. Boredom, as a purely action-related emotion, should result from a pattern of low control and low action values.

Pekrun's (2000) social-cognitive, control-value theory further states that the following aspects of a student's environment may be particularly relevant to the formation of his or her control and value cognitions: (1) quality of instruction, (2) induction of values, (3) feedback and consequences of achievement, and (4) expectations and goal structures. In selecting aspects of the classroom environment to be included in the present study, importance was placed on covering all four of these areas. We sought to include a well-balanced mixture of positive and negative aspects of the classroom environment, and to include constructs relating to both the teacher and the class community. There was, however, a concurrent need for parsimony and a restricted set of predictors due to the susceptibility of regressions to multicollinearity. The deliberations presented above, paired with the scattered empirical findings from the literature on classroom environments and emotions, resulted in selection of the following four facets of the mathematics classroom environments in the present study: (1) perceived quality of instruction (including clarity and structure); (2) perceived peer esteem of mathematics (i.e., the degree to which classmates are perceived to like and appreciate the subject); (3) perceived failure-contingent teacher punishment; and (4) perceived competition among peers (indicating competitive goal structures in the classroom).

Applying control-value theoretical assumptions, we posited that perceived quality of instruction and peer esteem would be conducive to the formation of positive action values. Attending classes with high quality mathematics instruction and being surrounded by peers who display a liking for the subject should contribute to positive values of 
mathematics-related activities. Therefore, high perceived quality of instruction and peer esteem should enhance enjoyment and reduce boredom in mathematics. In addition, the student who considers instruction to be clear and structured ought, on account of feeling assisted in penetrating the learning material and thus more competent in the respective subject, to hold higher individual control appraisals. Perceived quality of instruction should therefore not only increase enjoyment and decrease boredom, but also help to reduce anxiety and anger in relation to the given subject.

Furthermore, achievement-contingent punishment on the part of the teacher should produce a high value of achievement outcomes (particularly high negative value of failure). Consequently, we expected that perceived punishment from the teacher would be positively related to anxiety and anger. Finally, competitive goal structures in the classroom imply negative contingencies of success probabilities among the students; that is to say, the success of some students entails the failure of others (Johnson \& Johnson, 1974). Therefore, a student who perceives the classroom goal as competitive will perceive the chance of being successful as limited. Consequently, perceived competition among peers should be related to high values of achievement outcomes (i.e., high positive value of success and high negative value of failure). This ought to enhance any outcome-related emotion, including positive emotions following success (e.g., enjoyment) and negative emotions following failure (e.g., anxiety and anger).

The formulation of these assumptions rested on the central underlying notion that facets of the environment influence a student's cognitions and emotions. However, it is important to state that we did not assume the effects of proximal environments on a student's control and value beliefs and emotions to be unidirectional, but rather reciprocal (e.g., Pekrun, 2000; Pekrun et al., 2002b). Accordingly, a students' emotional experience may also influence how he or she perceives the environment. Moreover, students' emotional experiences almost certainly cause them to shape and influence their environments in various ways.

\section{Methodological considerations}

A range of approaches can be adopted in investigating the relationships between perceptions of the classroom environment and student outcomes. The most common of these is to relate individual perceptions of the environment to individual outcomes. Of the studies presented above, this approach has been used by Pekrun (1992), Jacob (1996), and Goetz et al. (2006) and the studies summarized by Hembree (1988). Data obtained using this approach provide useful information regarding the potential effects of classroom characteristics on psychosocial variables, assuming that these perceptions are an entirely individualized process and that the effects are only active at the individual level. A problem with this approach, however, is that it does not take into account the fact that students are grouped together in classes, thus violating the independence of observations requirement (Burstein, 1980). Furthermore, no attempt is made to include "shared" views of the classroom environment in such analyses.

A second approach uses data from self-report classroom environment measures which are aggregated across the whole class by taking the arithmetic mean. These average class perceptions are then correlated with the classes' means of the anent outcome variables. Of the studies presented above, Helmke (1983) and Fraser and his colleagues (e.g., Fraser \& Fisher, 1982) adopted this second approach. Within this approach, the deviation of each individual student's perception from the class mean is regarded as measurement error, based on the argumentation that personality factors such as trait anxiety may distort one's perception (e.g., Spielberger, 1972). Consequently, the average score of all students within a class is assumed to represent a more reliable index of the actual class environment (see Haertel, Walberg, \& Haertel, 1981). Finding relationships between perceived classroom environment and potential outcomes at the class level does not, however, allow one to infer that the same relationship is also true at the individual level. Doing so would be a typical case of ecological fallacy (Robinson, 1950). Still, findings at the collective level may convey useful information for teachers concerning the way in which average levels of enjoyment or boredom are affected by various aggregate perceptions of the classroom environment. This information could aid teachers in creating positively functioning classrooms.

Multilevel modelling is a statistical approach that elegantly integrates analyses at both the individual and the collective level by taking the nested structure of data (students being grouped together in classes) into account. Within this method, variance within classes and variance between classes are systematically disentangled, such that individual and aggregate predictors can be simultaneously accounted for. Standard errors are also more appropriately calculated than standard ordinary least square regressions with multilevel data and varying class sizes are taken into account (Keeves \& Cheung, 1990; Raudenbush \& Bryk, 2002). Using a multilevel approach, it is possible to simultaneously 
estimate: (1) individual-level effects; (2) class-level effects; and (3) compositional effects. The latter occur when the aggregate perception (e.g., the class' mean perceived quality of instruction) or indexes of the class' composition (e.g., gender ratio) influence a student's emotional experience, while his or her individual perception of the teacher or individual characteristic is controlled for (Raudenbush \& Bryk, 2002). Such compositional effects have aroused considerable interest and debate within organizational sociology (e.g., Erbring \& Young, 1979; Willms, 1986). Insight from these discussions can be applied to educational settings (e.g., Van Damme \& Opdendakker, 2004). In the present context, compositional effects offer particularly interesting information resulting from the use of multilevel modelling and extending beyond the information which is gained from individual and aggregated correlational approaches.

A few recent studies have used this approach in analysing relationships between learning environments and student outcomes. For example, Urdan (2004) showed that aggregate perceptions of classroom mastery goal structures were significantly related to individual values, self-efficacy and end-of-semester grades in English, even when individual goal structures were controlled for (compositional effects). Similarly, Karabenick (2004) reported that student help seeking was negatively related to individual and aggregate class-level perceptions of classroom performance-avoidance goal structures. Nolen (2003) showed that average student perceptions of instruction in their science classes as being meritocratic (i.e., fast paced and concentrating on errors) were negatively related to individual science achievement and moreover, shared perceptions that classrooms focused on understanding and independent thinking was positively related to individual student satisfaction with learning. Turner et al. (2002) showed that aggregate student perceptions of mastery goal structures influenced individual self-handicapping and avoidance of help seeking. However, both Nolen (2003) and Turner et al. (2002) incorporated the classroom environment variables at the class level only, so that individual level and class-level effects cannot be disentangled in their studies. Currently, we know of no study addressing student emotions as outcomes of their perceptions of the classroom environment with the use of hierarchical linear modelling procedures.

\section{Research questions and goals of the present study}

In summary, only few studies have analysed perceived characteristics of the classroom environment and their relationship to student academic emotions. Furthermore, to date, researchers have generally used either an individual or an aggregated approach and evidence using multilevel approaches which are able to disentangle individual- and classlevel effects thus seems to be widely lacking. Empirical data and theoretical deliberation lead us to suggest that perceived classroom environment is related to students' emotional experiences. We chose to include the emotions of enjoyment, anxiety, anger, and boredom in mathematics due to the fact that these emotions rate among the most intensely and frequently experienced emotions within academic settings (e.g., Pekrun et al., 2002b).

In order to identify "net relationships" of perceived classroom environment and student emotions, we strived to control for a number of individual and class variables constituting potentially important covariates of the perceptions of the classroom environment and of emotional experiences. Specifically, we incorporated mathematics achievement in terms of students' grades into our analyses. Mathematics achievement can be assumed to be related to both the perceptions of the classroom environment (e.g., Fraser, 1994; McRobbie \& Fraser, 1993) and the emotions experienced in mathematics (e.g., Pekrun et al., 2002b), and should therefore be integrated as a covariate. Secondly, we controlled for gender which has also been shown to be related to environment perceptions (e.g., Goh \& Fraser, 1998), as well as to mathematics emotions (Hyde, Fennema, Ryan, Frost, \& Hopp, 1990; Frenzel, Pekrun, \& Goetz, in press). We chose to integrate these covariates both at the individual and at the classroom level. The integration of achievement at both levels is useful in accounting for potential "Big-Fish-Little-Pond Effects" on student affective outcomes. These have been shown for self-concept (e.g., Marsh, 1987), test anxiety (Zeidner \& Schleyer, 1998), and mathematics anxiety and enjoyment (Goetz et al., 2004). Furthermore, findings reported by Helmke (1983) and Dryler (1999) suggest that not only gender as an individual-level predictor, but also gender ratio as a classroom characteristic may be predictive of student outcomes including test anxiety and educational choices. Finally, we integrated grade level and academic demands (in terms of school type) as control variables at the class level.

In sum, the present study pursued two major aims:

(1) We strived to confirm that students' perceptions of the classroom environment were related to their emotional experiences in mathematics when controlling for individual and class-level covariates. Using multilevel regression 
analysis with perceptions of the environment as predictors and emotions as criteria, we formulated the following hypotheses.

a. Perceived quality of instruction positively predicts enjoyment and negatively predicts anxiety, anger, and boredom.

b. Perceived positive peer esteem positively predicts enjoyment and negatively predicts boredom.

c. Perceived punishment on the part of the teacher positively predicts anxiety and anger.

d. Perceived competition among classmates positively predicts both enjoyment and anxiety and anger.

(2) We set out to explore compositional effects. We speculated that not only the individual perception of a student's mathematics classroom environment but also class' aggregate perceptions of the environment could play a role in the prediction of his or her experiences of mathematics emotions.

\section{Method}

\subsection{Participants and procedure}

The sample consisted of 1623 students ( $47.6 \%$ female) from 69 regular co-ed classes across grades 5-10 from the German state of Bavaria. The average class size was 22. On average, classes had a male proportion of 53\%. The gender ratio (number of boys by total number of students in class) was normally distributed across the classes. There was each one class with girls and boys only. Students were recruited from all three school types of the German state school system. In this system, the school type with the lowest academic demands is the "Hauptschule", which is predominantly vocationally oriented. The "Realschule" is the second school type and offers a curriculum of general education also laying the foundation for a future vocational career. The Realschule further provides opportunities for fulfilling prerequisites for passing over to a higher level of education and acquiring a certificate which subsequently opens the door to higher education. Third, there is the "Gymnasium" with the highest academic demands. Passing the final examination of the Gymnasium entitles students to study at university level. The sample was fairly representative of the Bavarian population of students between the ages of 10 and 16. Table 1 presents the number of students and classes in each grade level and school type.

Assessment took place shortly after mid-term by external, trained testing staff. Students were informed that the surveys were not to be considered as tests and that they would not be seen by their teacher or other school staff. Testing time for the entire questionnaire, which included a number of additional scales not presented in the current study, was approximately $70 \mathrm{~min}$.

\subsection{Measures}

\subsubsection{Classroom environment}

We assessed students' individually perceived classroom environment using four self-developed scales. These scales were (1) perceived quality of mathematics instruction; (2) perceived peer esteem of mathematics; (3) perceived punishment on the part of the mathematics teacher; and (4) perceived competition in the mathematics class. Various

Table 1

Composition of sample: number of participating students and classes in each grade and school type

\begin{tabular}{|c|c|c|c|c|c|c|c|c|}
\hline \multirow[t]{3}{*}{ Grade } & \multicolumn{6}{|c|}{ School type } & \multirow{2}{*}{\multicolumn{2}{|c|}{ Total }} \\
\hline & \multicolumn{2}{|c|}{ Hauptschule } & \multicolumn{2}{|c|}{ Realschule } & \multicolumn{2}{|c|}{ Gymnasium } & & \\
\hline & Students & Classes & Students & Classes & Students & Classes & Students & Classes \\
\hline 5 & 99 & 4 & 98 & 4 & 102 & 4 & 299 & 12 \\
\hline 6 & 70 & 4 & 85 & 3 & 100 & 4 & 255 & 11 \\
\hline 7 & 59 & 3 & 121 & 4 & 94 & 4 & 274 & 11 \\
\hline 8 & 96 & 5 & 113 & 4 & 103 & 4 & 312 & 13 \\
\hline 9 & 104 & 5 & 88 & 4 & 100 & 4 & 292 & 13 \\
\hline 10 & 17 & 1 & 88 & 4 & 86 & 4 & 191 & 9 \\
\hline Total & 445 & 22 & 593 & 23 & 585 & 24 & 1623 & 69 \\
\hline
\end{tabular}


sources were drawn upon for item formulation (Baumert, Gruehn, Heyn, Köller, \& Schnabel, 1997; Eder, 1998; Fraser, 1990; Moos \& Trickett, 1974; Pekrun, 1983; Von Saldern \& Littig, 1987), and adapted for domain-specific assessment. Item selection followed theoretical and empirical deliberation. Respondents were asked to express their degree of agreement or disagreement on a five-point Likert scale with response alternatives of strongly agree, mostly agree, partly agree, mostly disagree, and strongly disagree. All items and scales yielded satisfactory item-total correlations and alpha reliabilities. Table 2 shows sample items and reliabilities for all four scales at the individual level in terms of Cronbach's Alpha. Since the aggregated class scores of these scales were also integrated as predictors on the class level, reliabilities at the class level in terms of the intraclass correlations adjusted for the average class size of 22 in our study (ICC(2); see Bliese, 2000) are also displayed.

\subsubsection{Academic emotions}

Measurement of students' enjoyment, anxiety, anger, and boredom in relation to the subject of mathematics was carried out using the mathematics-related variant of the Academic Emotions Questionnaire (AEQ-M; Pekrun, Goetz, \& Frenzel, 2005). Respondents were once again asked to express their degree of agreement or disagreement on the five-point Likert Scale described above. The AEQ (English, German and Chinese versions) has been successfully implemented in both university and school settings, whereby reliability and validity of the instrument have been demonstrated (Pekrun, Goetz, \& Perry, 2005; Pekrun et al., 2002b; Frenzel, Thrash, Pekrun, \& Goetz, 2007). The number of items for each scale ranges between six and nine. Table 3 presents sample items and reliabilities for each of the four emotion scales as obtained in the present sample.

\subsubsection{Mathematics achievement}

Students' mathematics achievement was recorded on the basis of their current mid-term grades in mathematics. This mid-term grade represents the teacher-based judgment of the students' oral and written performances in mathematics over the first half of the year. German grades range from 1 to 6,1 being the top grade. For the present analyses, these grades were inverted such that higher values indicated higher achievement.

\subsection{Data analysis procedures}

\subsubsection{Data preparation}

At level 1, the individual student level, answers to the self-report items assessing classroom environment perceptions and emotions were $z$-standardized, and sum scales were calculated by taking the arithmetic mean. The selfreport sum scales were again $z$-standardized across the entire sample. We also $z$-standardized mathematics grade and the covariates gender, school type and grade level such that the regression weights of the hierarchical linear regressions were comparable and all expressed in the same metric. At level 2, mean class scores of classroom environment perceptions and emotions were calculated by taking the arithmetic mean for each class of students. The variable "gender ratio" was computed by dividing the number of boys in the class by the total number of its students. Zero-order correlations between perceptions of the mathematics classroom and emotions, both at the individual and at the class level, are provided in the Appendix. Zero-order correlations at the individual, within-class level are shown in the upper part of the Appendix. These values controlled for effects of class differences by subtracting students' scores from their respective class means. Correlations at the class level are shown in the lower part of Appendix. Since our sample was adequately large (both individuals and groups), we derived these correlations using

Table 2

Sample items and reliabilities for the assessment of perceived classroom environment in mathematics

\begin{tabular}{|c|c|c|c|c|}
\hline \multirow[t]{2}{*}{ Scale } & \multirow[t]{2}{*}{ Sample item } & \multicolumn{3}{|l|}{ Reliability } \\
\hline & & $\begin{array}{l}\text { Number of } \\
\text { items }\end{array}$ & $\begin{array}{l}\text { Ind. } \\
\text { level }\end{array}$ & $\begin{array}{l}\text { Class } \\
\text { level }\end{array}$ \\
\hline Quality of instruction & Our mathematics teacher makes sure that everybody understands the material. & 13 & 0.95 & 0.90 \\
\hline $\begin{array}{r}\text { Peer esteem of } \\
\text { mathematics }\end{array}$ & Most of the students in my class think that mathematics is cool. & 6 & 0.78 & 0.86 \\
\hline Teacher's punishment & My mathematics teacher scolds me when I do badly on a test. & 4 & 0.81 & 0.84 \\
\hline Competition & In my mathematics class everybody tries to outperform the others. & 9 & 0.84 & 0.80 \\
\hline
\end{tabular}


Table 3

Sample items and reliabilities for the assessment of mathematics emotions

\begin{tabular}{llll}
\hline Emotion & Sample item & Number of items & Cronbach's Alpha \\
\hline Enjoyment & I look forward to my mathematics class. & 8 & 0.90 \\
Anxiety & Before a mathematics test, I am so anxious that I'd rather not take it. & 9 & 0.87 \\
Anger & My mathematics homework makes me angry. & 6 & 0.87 \\
Boredom & I am so bored in my mathematics class that I can hardly stay awake. & 6 & 0.88 \\
\hline
\end{tabular}

Muthén's pseudo-balanced approach to the scaled between-group covariance matrix (see Hox, 2002, p. 228; and Muthén, 2004, p. 44ff).

\subsubsection{Multilevel modelling}

In a preliminary analysis step to the multilevel modelling procedures, we examined classroom environment scales as dependent variables and calculated the proportions of within- and between-class variance (intraclass correlations) of these perceptions. This enabled us to determine the degree of class consensus concerning assessed aspects of classroom environment. Subsequently, three steps were taken in investigating the relationship between perceived classroom variables and students' academic emotions by applying hierarchical linear modelling procedures (HLM 5.04, Raudenbush, Bryk \& Congdon, 2005). In Step 1, the fully unconditional models, proportions of within- and between-class variance were calculated for enjoyment, anxiety, anger, and boredom (intraclass correlations). This is a crucial preliminary analysis which shows whether higher-order analyses are required: if the proportion of variance attributable to the classes is not significant, further analyses can be dispensed with. The fully unconditional model is then to be extended by successive introduction of covariates and predictors. In Step 2, mathematics achievement and gender were introduced at the individual level, and mean mathematics achievement, gender ratio, academic demands (school type), and grade level (5-10) were introduced at the class level. These analyses were required to ensure that differences between students and between classes were not mere effects of these covariates. Finally, in Step 3, environmental variables were introduced into the model. For each of these variables, individual scores were introduced on the individual level, and aggregate class scores at level 2 (limited, however, to the intercepts; slopes were considered as fixed). Consequently, the corresponding level-1 and level-2 equations were as follows:

Level 1:

$$
\begin{aligned}
\text { Emotion }(\text { of individual } i \text { in class } j)= & \left.\beta_{0 j}+\beta_{1 j} \text { (individual mathematics achievement }\right) \\
& \left.+\beta_{2 j} \text { (individual gender }\right) \\
& \left.+\beta_{3 j} \text { (individually perceived quality of instruction }\right) \\
& \left.+\beta_{4 j} \text { (individually perceived peer esteem }\right) \\
& +\beta_{5 j}(\text { individually perceived teacher punishment }) \\
& \left.+\beta_{6 j} \text { (individually perceived competition among peers }\right)+r_{i j}
\end{aligned}
$$

Level 2:

$$
\begin{aligned}
\beta_{0 j}= & \gamma_{00}+\gamma_{01}(\text { class mean mathematics achievement })+\gamma_{02}(\text { gender ratio in the class }) \\
& +\gamma_{03}(\text { school type })+\gamma_{04}(\text { grade level })+\gamma_{05}(\text { aggregate perceived quality of instruction }) \\
& +\gamma_{06}(\text { aggregate perceived peer esteem })+\gamma_{07}(\text { aggregate perceived teacher punishment }) \\
& +\gamma_{08}(\text { aggregate perceived competition among peers })+u_{0 j} \\
\beta_{10}= & \gamma_{10}, \beta_{20}=\gamma_{20}, \beta_{30}=\gamma_{30}, \beta_{40}=\gamma_{40}, \beta_{50}=\gamma_{50}, \beta_{60}=\gamma_{60}
\end{aligned}
$$

HLM thus calculates individual and class level effects simultaneously and disentangles within-class and betweenclass effects when predictors are centred around the class mean. In addition, when predictors are centred around the grand mean (i.e., with relation to the entire sample) we can test the significance of compositional effects (Raudenbush $\&$ Bryk, 2002). 


\section{Results}

\subsection{Preliminary analyses}

Preliminary analyses of the intraclass correlations of classroom perceptions showed that students shared considerable amounts of variance in their judgments. Intraclass correlations amounted to 0.29 for perceived quality of instruction, 0.22 for perceived peer esteem of mathematics, 0.19 for perceived punishment on the part of the teacher, and 0.15 for perceived competition among peers. All between-class variances significantly differed from zero $(p<0.01)$.

\subsection{Multilevel modelling}

\subsubsection{Steps 1-3: Intraclass correlations and explained variances}

In Step 1 of the multilevel analyses, fully unconditional models were run with each of the four emotions as criterion variables. By means of these analyses, baseline estimates of within-class as well as between-class variances were obtained and intraclass correlations were calculated. The between-class variances significantly differed from zero for all four emotions $(p<0.01)$, implying that classes systematically varied in their levels of experienced emotions. The intraclass correlations for enjoyment, anxiety, anger and boredom were $0.13,0.05,0.08$, and 0.08 , respectively. From this it could be inferred that significant amounts of the students' emotional experience can be traced back to their class affiliation. Environmental variables which explain this proportion of shared experience should therefore be found.

Next, in Step 2 (covariate models), potential individual and class-level covariates were introduced into the model, including mathematics achievement and gender at the individual level, and mean mathematics achievement, gender ratio, academic demands (school type), and grade level at the class level. In these models, variances in emotion scores among students within classes, as compared to variances obtained in the fully unconditional model, were reduced by $16 \%, 15 \%$, $11 \%$, and $6 \%$ for enjoyment, anxiety, anger, and boredom, respectively. At the class level, covariates carried more weight; between-class variances were reduced by $48 \%$ for enjoyment, $16 \%$ for anxiety, $32 \%$ for anger, and $37 \%$ for boredom. However, between-class variances remained significantly different from zero for each emotion $(p<0.01)$.

In Step 3, classroom characteristics were additionally entered at the individual level as well as at the class level (aggregated class scores). Final proportions of explained within-class and between-class variances are displayed in the lower part of Table 4. Within classes, $37 \%, 23 \%, 33 \%$, and $28 \%$ of the variance between students could be explained for enjoyment, anxiety, anger, and boredom, respectively. At the class level, even more substantial proportions of between-class variances could be explained by the introduced variables: $96 \%$ for enjoyment, $61 \%$ for anxiety, $94 \%$ for anger, and $81 \%$ for boredom. The residual between-class variances no longer significantly differed from zero for enjoyment, anger, and boredom $(p>0.01)$. From these results it can be concluded that the classroom variables integrated in our study were excellent predictors of the classes' mean experienced emotions.

\subsubsection{Effects of covariates on achievement emotions}

Table 4 presents regression coefficients of the individual predictors and class-level predictors for each emotion. All predictors and criteria had been $z$-standardized on the individual level, thus all of them are measured in the same metric and regression weights are comparable on this level. For these analyses, individual predictors were centred around the group means (i.e., with reference to their class means) such that person-level and class-level effects could clearly be distinguished. In order to identify significant compositional effect, we conducted the same analyses with individual variables centred around their grand means (Raudenbush \& Bryk, 2002). In cases where these analyses revealed a class-level effect significantly differing from the person-level effect, coefficients have been marked with italic print in Table 4.

Turning first to the individual level, mathematics achievement and gender were significantly related to individually reported enjoyment, anxiety, and anger. The higher the mathematics achievement, the more enjoyment, but less anxiety and anger the students reported to experience. Given the scoring of the nominal variable of gender, the beta weight for gender implies that boys reported higher levels of enjoyment and lower levels of anxiety and anger. The covariates were not significantly related to individual boredom.

Concerning the covariates at the class level, the classes' mean mathematics achievement was significantly related to their mean level of anxiety. Explicitly, the higher the average achievement, the lower the average anxiety across 
Table 4

Multilevel regression of individual and classroom covariates and perceived environment variables on enjoyment, anxiety, anger, and boredom: beta weights and explained variances

\begin{tabular}{|c|c|c|c|c|}
\hline \multirow[t]{2}{*}{ Predictor } & \multicolumn{4}{|l|}{ Emotion } \\
\hline & Enjoyment & Anxiety & Anger & Boredom \\
\hline \multicolumn{5}{|l|}{ Individual level } \\
\hline \multicolumn{5}{|l|}{ Classroom perceptions } \\
\hline Quality of instruction & $0.29 * *$ & $0.08 *$ & $0.24 * *$ & $0.20 * *$ \\
\hline Peer esteem & $0.32 * *$ & $0.17 * *$ & $0.31 * *$ & $0.35^{* *}$ \\
\hline Teacher's punishment & 0.01 & $0.12 * *$ & $0.14 * *$ & $0.11^{* *}$ \\
\hline Competition & $0.06 * *$ & $0.16^{* *}$ & $0.12 * *$ & $0.07 *$ \\
\hline \multicolumn{5}{|l|}{ Covariates } \\
\hline Mathematics achievement & $0.29 * *$ & $0.33 * *$ & $0.26 * *$ & $0.18^{* *}$ \\
\hline Gender & $0.12 * *$ & $0.21 * *$ & $0.10 * *$ & 0.02 \\
\hline \multicolumn{5}{|l|}{ Class level } \\
\hline \multicolumn{5}{|l|}{ Classroom perceptions } \\
\hline Quality of instruction & 0.08 & 0.02 & $0.15^{*}$ & 0.13 \\
\hline Peer esteem & $0.59 * *$ & $0.38 * *$ & $0.42 * *$ & $0.43 * *$ \\
\hline Teacher's punishment & 0.04 & 0.04 & 0.04 & $0.17 *$ \\
\hline Competition & 0.12 & 0.21 & $0.20 *$ & $0.23^{*}$ \\
\hline \multicolumn{5}{|l|}{ Covariates } \\
\hline Mean mathematics achievement & 0.07 & $0.16^{*}$ & 0.10 & 0.06 \\
\hline Gender ratio & $0.16^{*}$ & $0.16^{*}$ & 0.01 & 0.02 \\
\hline Academic demands (school type) & 0.03 & 0.03 & 0.01 & 0.01 \\
\hline Grade level & 0.01 & 0.07 & 0.02 & 0.04 \\
\hline Explained within class variance (\%) & 37 & 23 & 33 & 28 \\
\hline Explained between class variance $(\%)$ & $96^{\mathrm{a}}$ & 61 & $94^{\mathrm{a}}$ & $81^{\mathrm{a}}$ \\
\hline
\end{tabular}

Note: Predictor variables were all standardized and group mean centered. Gender was coded $0=$ female, $1=$ male; gender ratio represents the pro portion of boys in a class (number of boys by total student number). Coefficients printed in italic indicated compositional effects. $* p<0.05, * * p<0.01$.

${ }^{a}$ Residual between class variance no longer significantly differed from zero $(p>0.01)$.

classes. The same effect had been seen to occur at the individual level, but to a much stronger degree. This difference between the individual-level effect and the class-level effect was significant (as confirmed by analysis based on predictors centred around the grand mean). Hence, there is a compositional effect of achievement on anxiety implying that the average achievement level of the class in fact had a significantly positive effect on the individual experience of anxiety (i.e., the higher the class' average achievement, the more anxious the individual student). The same applied to the relationship between achievement and enjoyment, as well as between achievement and anger. These relationships were not significant in the context of between-class effects alone. However, due to the large discrepancy between within-class and between-class effects, these constituted compositional effects, indicating that the average achievement level of the class had a significantly negative effect on the individual experience of enjoyment and a significantly positive effect on the individual experience of anxiety and anger. In summary, our data suggest that the higher a student's achievement in mathematics, the higher his or her enjoyment of the subject and the lower his or her anxiety and anger. Simultaneously, the higher the student's class average achievement in mathematics, the less he or she will enjoy, and the more anxious and angry he or she will feel in relation to this subject.

The covariate gender ratio also influenced the experience of anxiety and enjoyment across classes. However, the effect was reversed compared to the individual level. Classes with more boys reported on average less enjoyment and increased levels of anxiety. Compositional effects were thus evident: class gender ratio proved to have a significant effect on the individual experience of enjoyment (this decreases, when the proportion of boys in the class increases) and anxiety (which increases, when the proportion of boys in the class increases). It should be noted that gender ratio and achievement were unrelated at the class level $(r=-0.08, p=0.50)$ which implies that the effects of gender ratio and achievement at the class level were independent. 
Neither academic demands (school type) nor grade level were associated with the average levels of achievement emotions across classes.

\subsubsection{Effects of perceptions of classroom environment on achievement emotions}

With regard to the individual perceptions of classroom variables, there were strong relationships between the perceived quality of instruction in mathematics on one hand and individual emotional experience of enjoyment, anger, and boredom on the other hand (see Table 4). The higher the students judged their mathematics teacher's quality of instruction, the more they reported to experience enjoyment, and the less they reported to experience anger and boredom. High individually perceived quality of instruction was also related to slightly reduced individual levels of anxiety in mathematics. Very strong effects were also found for perceived peer esteem, which was positively related to individually reported enjoyment and negatively related to anxiety, anger, and boredom. Moreover, individually perceived punishment behaviour on the part of the teacher was not related to the individual experience of enjoyment, but was significantly positively related to the experience of anxiety, anger, and boredom. Finally, individually perceived competition was not only positively related to individually experienced anxiety and anger, but also to enjoyment and boredom.

At the class level, we found mean perceived quality of instruction to be slightly positively related to a class' overall enjoyment level. However, this effect was considerably smaller at the class level compared to the individual level hence it was a compositional effect. It implies that the higher the class' average judgment of the mathematics teacher's quality of instruction, the lower the individual level of enjoyment of mathematics. Mean perception of quality of instruction was also negatively related to the classes' overall experience of anger.

Furthermore, we found strong effects for peer esteem also at the class level. Class mean perceived peer esteem was strongly positively related to enjoyment, but negatively related to anxiety, anger and boredom across classes. For enjoyment and anxiety, these class-level effects were significantly greater than the individual effects (compositional effects). A student of a class averagely perceiving mathematics to be valuable would thus experience greater enjoyment and less anxiety in the subject. Moreover, whereas boredom was positively related to the individual perception of the teacher as punitive, this relationship was negative at the class level. This yields a significant compositional effect, suggesting that a student of a class averagely judging their teacher to be punitive will be less bored. Finally, we found that the classes' mean anger and boredom levels were positively related to the mean perception of competition in the class.

\section{Discussion}

The main goal of the present study was an examination of the relationships between students' perception of their mathematics classroom environment and their experiences of enjoyment, anxiety, anger, and boredom in mathematics. We analysed these relationships using a multilevel approach which entailed the students' reported emotional experiences being simultaneously regressed on the individual-level and collective-level perceptions of the environment. Separate regression models were run for enjoyment, anxiety, anger, and boredom.

First of all, it should be noted that our results suggest that classes significantly differ in their mean levels of enjoyment, anxiety, anger, and boredom in mathematics. Average perceptions of the classroom environment could to a large extent explain these variations between classes in terms of their average emotional experiences. At the same time, we also conclude from our data that the relationships between perceived classroom environments and emotions predominantly function at the individual level. With within-class and between-class effects simultaneously accounted for, almost all predictors at the individual level significantly contributed to the explanation of variance in the reported emotions. In comparison, effects on the class level were lower and less frequently significant. A similar picture has been observed by Urdan (2004) when relating classroom goal structures to individual goals and other outcomes. Indeed, as Urdan argues, one reason for the greater power of individually perceived classroom environment may be that both independent and dependent variables are based on individual self-reports.

\subsection{Relationships between perceived classroom climate and emotions at both the individual level and the class level}

Perceived quality of instruction and perceived peer esteem proved to be positively related to the experience of enjoyment and negatively related to anxiety, anger and boredom. This fully confirms our expectations since we had assumed that highly perceived quality of instruction implies both control over outcomes in mathematics and 
a high regard (value) of activities in that domain, which, in turn, influence the students' activity- and outcome-related emotions in the subject (Pekrun, 1992, 2000). For perceived peer esteem in mathematics, whereby students judged what "most of their classmates" thought about the subject of mathematics" ("...is cool" - "...is a waste of time" as an inverted item, etc.), we had expected a relationship to the activity-related emotions of enjoyment and boredom. This was also clearly confirmed by our data. Additionally, however, perceived peer esteem also proved to be relatively strongly negatively related to anxiety and anger.

Furthermore, we had hypothesized that perceived failure-contingent punishment on the part of the teacher, conveying a high negative value of failure, would be positively linked to students' reported anxiety and anger. This was also confirmed in our analyses. In addition, perceived punishment proved to be slightly positively linked to boredom. Also in line with our predictions, we found that student perceptions of competitive goal structures - which we assume to induce a high negative value of failure but at the same time high positive value of success - were positively related to enjoyment, anxiety, and anger. Beyond our expectations, perceived competition was also slightly positively related to boredom.

\subsection{Compositional effects}

The second goal of the present study was the exploration of so-called compositional effects, which are present when an aggregated variable proves to impact the individual criterion even after this variable has been accounted for at the individual level (Raudenbush \& Bryk, 2002). Such compositional effects were found in the current study. Two concerned the covariates considered in our analyses, namely achievement and gender. Furthermore, the aggregate class perception of quality of instruction, teacher's punishment, and peer esteem also proved to play a significant role in the individual's experience of certain emotions.

In terms of the effect of achievement on emotional experience, we obtained a pattern of findings corresponding to the Big-Fish-Little-Pond Effect (Marsh, 1987). Whereas higher mathematics achievement in terms of mid-term grades was related to higher enjoyment and lower anxiety and anger at the individual level, higher mean levels of average achievement in the class seem to decrease the students' enjoyment and increase their anxiety and anger. Consequently, due to the presence of different reference groups, two students with the same grade (assume for example, grade 3 on the German 6-point grading scale with 1 reflecting the top grade) but from different classes, will emotionally react in different ways to that grade. The student from a highly achieving class with an average grade of 2.5 will be angry at his grade and may even develop anxiety when faced with an upcoming test because he feels as though he is lagging behind his peers. The student from a weaker class with an average achievement level of 3.5 will be rather happy with his grade 3 and will not be anxious about future exams due to the fact that he performed better than most of his peers. Such positive effects of individual achievement, paired with negative effects of class level achievement have been repeatedly reported for academic self-concepts (Marsh, 1987), but also for test anxiety in gifted students (Zeidner \& Schleyer, 1998), and enjoyment and anxiety in mathematics among regular students (Goetz et al., 2004). The present study therefore replicates these findings for enjoyment and anxiety and extends them to incorporate the emotion of anger.

Furthermore, individual gender and gender ratio of the class proved to be differentially linked to the individual experience of enjoyment and anxiety in mathematics. On one hand, males reported to experience more enjoyment and less anxiety in mathematics than females, yet on the other hand, students in classes with a higher ratio of boys seemed to experience more anxiety and less enjoyment in mathematics. Thus, "male-dominated" classes appear to show more negative emotional patterns than classes with high numbers of girls. Above all, girls in male-dominated mathematics classes seem to be the most disadvantaged. Their negative emotional pattern in relation to the subject of mathematics (less enjoyment, more anxiety than boys) is even more enhanced if they find themselves in maledominated classes. Further research should aim to replicate and explain this effect.

It was thus conspicuous that there were more negative emotional patterns in classes with higher achievement levels and in classes with a higher proportion of boys. However, there was no systematic relationship between gender ratio and average achievement of the classes. Therefore, we concluded that the effects of gender ratio and achievement at the class level on the emotional experience can be assumed to be independent of each other.

We also found that perceived quality of instruction and emotional experiences were differentially linked at the individual and class level. Whereas individual perceptions of the teacher as being clear and structured is related to higher levels of enjoyment, a high average perceived level of quality of instruction in the class will decrease the student's enjoyment. It could be speculated that this can again be interpreted in terms of fish-pond effects. This would 
imply that high average perceived quality of instruction corresponds to higher achievement demands in the respective class and probably also to higher pacing (e.g., Barr \& Dreeben, 1983), which in turn seem to negatively influence the individual's experience of enjoyment of mathematics in that class.

Moreover, there was a compositional effect for the relationship between perceived teacher's punishment behaviour and boredom. At the individual level, this relationship was positive, thus, the more frequently a student perceives teacher punishment, the more boredom he or she will report. However, at the collective level, we find the reversed effect; the more frequently a class perceives teacher punishment on average, the less overall boredom they will experience. In this case, it may be that the aggregated score measures something other than the individual perception (see also Raudenbush \& Bryk, 2002; or Willms, 1986, for such an interpretation of compositional effects), that is to say, a high overall level of perceived punishment may represent the teacher's engagement and involvement in the class, which is associated with lower overall boredom levels. This explanation may help elucidate the data patterns found in the present study; it remains, however, a mere after-the-fact speculation, requiring empirical investigation.

Finally, we found consistent compositional effects of peer esteem on enjoyment and anxiety. It can be assumed that a student experiences more enjoyment in mathematics if he or she thinks that their peers appreciate the subject. In addition, this will be enhanced if the student is surrounded by classmates who indeed on average highly regard the subject. The reverse pattern occurred for anxiety; a student's perception of his or her classmates as appreciating the subject is accompanied by decreased anxiety, and this effect is enhanced if the student is surrounded by classmates who, on average, think the same way. Actual average class attitudes and not only individual perceptions of these therefore seem to be relevant in predicting a student's experience of enjoyment and anxiety in mathematics.

\subsection{Limitations of the present study}

It is important to note that even though the present study examined students' emotions as dependent variables and environmental variables as predictors, the cross-sectional nature of the data does not permit cause-effect relationships to be inferred. Theoretically, we do assume reciprocal connections between aspects of the environment and students' emotional experiences. For example, not only do we presuppose that the perception of the environment influences students' emotions, but also that the way they feel towards mathematics will shape their perceptions of the environment. This may, for example, apply to the perception of the quality of instruction and peer esteem; the more positive a student's emotions towards the subject, the more 'generously' he will judge his teacher and classmates with regard to their behaviour and attitudes. In addition, a student's emotions may also lead him to behave in a certain way, which in turn shapes his environment accordingly. We assume that such mechanisms may underlie the relationship between boredom and punishment; the student who is bored will be inattentive and noisy, creating disciplinary problems in the classroom and causing the teacher to punish him.

Furthermore, the relationship between perceived classroom environment and emotional experience was investigated in the mathematics classroom only and it will be of importance to examine these hypotheses in other subject domains. The current sample was also restricted to secondary education; different relationships may be found at the primary level. Finally, we are aware that compositional effects, as they were described in the present study (with predictors simultaneously introduced both at the individual and at the collective level), may constitute mere artefacts rather than truly interpretable data in the case that the effects on the individual and at the collective level are in the same direction (Lüdtke, Robitzsch, \& Köller, 2002; Tymms, 2004). This may apply to the reported effect of peer esteem on enjoyment and anxiety. Conducive to the emergence of such artificial compositional effects are low reliability and high intraclass correlations of the individual predictors (Lüdtke et al., 2002). In view of the high reliabilities of all our predictors (Cronbach Alpha $\geq 0.70$ ) at the individual level and the only moderate intraclass correlations (intraclass correlations $\leq 0.21$ ) we do, however, consider these effects to be "true" as opposed to artificial effects.

\subsection{Educational implications}

Gathering together the findings of our study, we believe that the following recommendations could be inferred for the classroom. First, given the relatively close links between perceived quality of instruction and the 
emotional experiences in relation to mathematics, efforts to improve clarity and structuredness of instruction, and keeping track of levels of students' comprehension should help to build a positive emotional atmosphere in the classroom.

Second, we conjecture that teachers are able to influence and mould students' value beliefs in the subjects they teach. These value beliefs appear to be closely linked to students' emotional experiences. Teachers deliver both direct, verbal messages concerning academic values, as well as more indirect messages conveyed through their behaviour, and the learning assignments given to students. We believe that teachers can promote the development of values by shaping instructional material, assigned tasks, and classroom interaction (Krapp, 2005), using authentic learning tasks and providing a classroom discourse that engages all students. In addition, by way of observational learning and emotional contagion (Hatfield, Cacioppo, \& Rapson, 1994), teachers' own enthusiasm in dealing with academic material is likely to facilitate students' absorption of values.

Moreover, students' perception of being punished after failure was positively related to their experience of negative emotions in our study. In view of the emotional well-being of students, our data thus lend support to the recommendation that achievement-contingent punishment be avoided. Incentives for desired learning- and class-related behaviours rather than punishment for negative outcomes should guide educators' attempts to shape student behaviour (see Weinstein, 1999, for a similar view).

Finally, given the ambivalent finding in the current study that perceived competition among classmates was positively linked to both positive and negative emotions, our findings appear to support recommendations for a combination of cooperative and competitive goal structures in the classroom. This can, for example, be achieved through activities involving within-group cooperation paired with between-group competition (e.g., Slavin, 1994). Such activities should enhance student perceptions of success as rewarding and enjoyable, but not failure as individually punishing and anxiety- or anger-provoking.

\section{Summary and conclusion}

Beyond the well-researched phenomenon of test anxiety, academic emotions have received relatively little attention within educational research. Findings of the present study showed that anxiety, anger, and boredom in relation to the subject of mathematics are differentially affected by facets of the classroom environment as perceived by students. We also showed that classes systematically differ from one another in their levels of experienced emotions, and that this variance can to a large extent be explained by class variables and mean perceptions of classroom environment characteristics. Our data also support the assumption that an individual's emotional experience is not only influenced by how he or she perceives the environment, but also by the composition of the class in terms of gender ratio and achievement level, and by the average perceptions of the student body in a classroom. This information is of particular value for educators, for whom the affective well-being of their students should be a desired educational goal in itself.

\section{Appendix. Zero-order correlations between perceived classroom environment variables and achievement emotions: within-class individual level and between-class level}

\begin{tabular}{lcccc}
\hline & Quality of instruction & Peer esteem & Teacher punishment & Peer competition \\
\hline Within class individual level correlations & & & 0.14 & 0.08 \\
Enjoyment & 0.44 & 0.45 & 0.18 & 0.14 \\
Anxiety & 0.23 & 0.26 & 0.26 & 0.12 \\
Anger & 0.40 & 0.42 & 0.23 & 0.08 \\
Boredom & 0.36 & 0.41 & & 0.51 \\
Scaled between class correlations & & 0.00 & 0.17 \\
Enjoyment & 0.65 & 0.88 & 0.41 & 0.12 \\
Anxiety & 0.39 & 0.50 & 0.35 & 0.22 \\
Anger & 0.69 & 0.80 & 0.11 & \\
Boredom & 0.59 & 0.75 & & \\
\hline
\end{tabular}




\section{References}

Anderman, E. (2002). School effects on psychological outcomes during adolescence. Journal of Educational Psychology, 94, 795-809.

Anderman, E., Eccles, J., Yoon, K., Roeser, R., Wigfield, A., \& Blumenfeld, P. (2001). Learning to value math and reading: individual differences and classroom effects. Contemporary Educational Psychology, 26, 76-95.

Barr, R., \& Dreeben, R. (1983). How schools work. Chicago, IL: University of Chicago Press.

Baumert, J., Gruehn, S., Heyn, S., Köller, O., \& Schnabel, K. U. (1997). Bildungsverläufe und psychosoziale Entwicklung im Jugendalter (BIJU), Dokumentation [Learning processes, educational careers, and psychosocial development in adolescence and young adulthood, Documenta tion]. Berlin: Max Planck Institute for Educational Research for Human Development.

Bliese, P. D. (2000). Within group agreement, non independence, and reliability: implications for data aggregation and analysis. In K. J. Klein, \& S. W. J. Kozlowski (Eds.), Multilevel theory, research, and methods in organizations (pp. 349-381). San Francisco: Jossey Bass.

Brophy, J. (1999). Teaching. Brussels: International Academy of Education.

Burstein, L. (1980). Issues in the aggregation of data. In D. C. Berlinger (Ed.), Review of Research in Education, 8 (pp. 158-233).

Dryler, H. (1999). The impact of school and classroom characteristics on educational choices by boys and girls: a multilevel analysis. Acta Sociologica, 42, 299-318.

Eder, F. (1998). Linzer Fragebogen zum Schul und Klassenklima für die 8. 13. Klasse (LFSK 8-13) [Questionnaire on school and classroom climate for grades 8-13]. Göttingen: Hogrefe.

Erbring, L., \& Young, A. A. (1979). Individuals and social structure: contextual effects as endogenous feedback. Sociological Methods and Research, 7, 396-430.

Fennema, E., \& Sherman, J. (1976). Fennema-Sherman Mathematics Attitude Scales. JSAS: Catalog of Selected Documents in Psychology, 6(1), 31, (Ms. No. 1225).

Fraser, B. J. (1990). Individualized classroom environment questionnaire. Melbourne: Australian Council for Educational Research.

Fraser, B. J. (1994). Research on classroom and school climate. In D. L. Gabel (Ed.), Handbook of research on science teaching and learning (pp. 493-541). New York: Macmillan.

Fraser, B. J., \& Fisher, D. L. (1982). Predicting students' outcomes from their perceptions of classroom psychosocial environment. American Educational Research Journal, 19, 498-518.

Fraser, B. J., \& Walberg, H. J. (1991). Educational environments: Evaluation, antecedents and consequences. Oxford, GB: Pergamon.

Frenzel, A. C., Pekrun, R., \& Goetz, T. (in press). Girls and mathematics a "Hopeless" issue? A control value approach to gender differences in emotions towards mathematics. European Journal of Psychology of Education.

Frenzel, A. C., Thrash, T. D., Pekrun, R., \& Goetz, T. (2007). Achievement emotions in Germany and China: A cross cultural validation of the academic emotions questionnaire-mathematics. Journal of Cross Cultural Psychology, 38, 302-309.

Goetz, T., Pekrun, R., Hall, N., \& Haag, L. (2006). Academic emotions from a social cognitive perspective: antecedents and domain specificity of students' affect in the context of Latin instruction. British Journal of Educational Psychology, 76(2), 289-308.

Goetz, T., Pekrun, R., Zirngibl, A., Jullien, S., Kleine, M., \& vom Hofe, R., et al. (2004). Leistung und emotionales Erleben im Fach Mathematik: Längsschnittliche Mehrebenenanalysen [Academic achievement and emotions in mathematics: a longitudinal multilevel analysis perspective]. Zeitschrift für Pädagogische Psychologie, 18, 201-212.

Goetz, T., Zirngibl, A., \& Pekrun, R. (2003). Lern und Leistungsemotionen von Schülerinnen und Schülern [Students' achievement emotions]. In T. Hascher (Ed.), Schule positive erleben. Ergebnisse und Erkenntnis zum Wohlbefinden von Schülerinnen und Schülern (pp. 49-66). Bern, Switzerland: Haupt.

Goh, S. C., \& Fraser, B. J. (1998). Teacher interpersonal behavior, classroom environment and student outcomes in primary mathematics in Singapore. Learning Environments Research, 1, 199-229.

Haertel, G. D., Walberg, H. J., \& Haertel, R. (1981). Socio psychological environments and learning: a quantitative synthesis. British Educational Research Journal, 7, 27-36.

Hatfield, E., Cacioppo, J. R., \& Rapson, R. L. (1994). Emotional contagion. Current Directions in Psychological Science, 2, 96-99.

Helmke, A. (1983). Schulische Leistungsangst [Scholastic fear of achievement]. Frankfurt, Germany: Lang Verlag.

Hembree, R. (1988). Correlates, causes, effects and treatment of test anxiety. Review of Educational Research, 58, 47-77.

Hox, J. (2002). Multilevel analysis: Techniques and applications. Mahwah, New Jersey: Lawrence Erlbaum.

Hyde, J. S., Fennema, E., Ryan, M., Frost, L. A., \& Hopp, C. (1990). Gender comparisons of mathematics attitudes and affect: a meta analysis. Psychology of Women Quarterly, 14, 299-324.

Jacob, B. (1996). Leistungsemotionen bei Schülern [Students' achievement emotions]. Unpublished Master's Thesis, University of Regensburg, Germany.

Johnson, D. W., \& Johnson, R. T. (1974). Instructional goals structure: cooperative, competititve or individualistic. Review of Educational Research, 4, 213-240.

Karabenick, S. A. (2004). Perceived achievement goal structure and college student help seeking. Journal of Educational Psychology, 96, 569-581.

Keeves, J. P., \& Cheung, K. C. (1990). Changing strategies of analysis: towards multilevel models. In K. C. Cheung, J. P. Keeves, N. Sellin, \& S. C. Tsoi (Eds.), Analysis of multilevel data in educational research: Studies of problems and their solutions. International Journal of Educational Research, 14, 215-319.

Krapp, A. (2005). Basic needs and the development of interest and intrinsic motivational orientations. Learning and Instruction, 15, 381-395.

Larson, R. W., \& Richards, M. H. (1991). Boredom in the middle school years: blaming schools versus blaming students. American Journal of Education, 99, 418-443. 
Lüdtke, O., Robitzsch, A., \& Köller, O. (2002). Statistische Artefakte bei Kontexteffekten in der pädagogisch psychologischen Forschung [Statistical artefacts in educational studies on context effects]. Zeitschrift für Pädagogische Psychologie, 16, $217-231$.

McRobbie, C. J., \& Fraser, B. J. (1993). Associations between student outcomes and psychosocial science environment. Journal of Educational Research, 87, 78-85.

Marsh, H. W. (1987). The Big Fish Little Pond Effect on academic self concept. Journal of Educational Psychology, 79, $280-295$.

Moos, R. H. (1979). Evaluating environments: Measures, procedures, findings and policy implications. San Francisco, CA: Jossey Bass.

Moos, R. H., \& Trickett, E. J. (1974). Classroom environment scale manual. Palo Alto, CA: Consulting Psychologists Press.

Muthén, B. O. (2004). Mplus technical appendices. Los Angeles, CA: Muthén \& Muthén.

Nolen, S. B. (2003). Learning Environment, motivation, and achievement in High School science. Journal of Research in Science Teaching, 40, 347-368.

Pekrun, R. (1983). Schulische Persönlichkeitsentwicklung. Theorieentwicklung und empirische Erhebungen zur Persönlichkeitsentwicklung von Schülern der 5. bis 10. Klassenstufe [Personality development at school: Theory and empirical data on the development of students' personality during the grades 5-10]. Frankfurt, Germany: Lang Verlag.

Pekrun, R. (1992). Expectancy value theory of anxiety: overview and implications. In D. G. Forgays, T. Sosnowski, \& K. Wresniewski (Eds.), Anxiety: Recent developments in cognitive, psychophsysiological and health research (pp. 23-41). Washington, DC: Hemisphere.

Pekrun, R. (2000). A social cognitive, control value theory of achievement emotions. In J. Heckhausen (Ed.), Motivational psychology of human development (pp. 143-163).

Pekrun, R., Goetz, T., \& Frenzel, A. C. (2005). Academic emotions questionnaire - Mathematics (AEQ M) - User's manual. Department of Psychology, University of Munich.

Pekrun, R., Goetz, T., \& Perry, R. P. (2005). Academic emotions questionnaire (AEQ) - User's manual. Department of Psychology, University of Munich.

Pekrun, R., Goetz, T., Titz, W., \& Perry, R. P. (2002a). Positive emotions in education. In E. Freydenberg (Ed.), Beyond coping: Meeting goals, visions, and challenges (pp. 149-174). Oxford, UK: Elsevier.

Pekrun, R., Goetz, T., Titz, W., \& Perry, R. P. (2002b). Academic emotions in students' self regulated learning and achievement: a program of qualitative and quantitative research. Educational Psychologist, 37, 91-105.

Raudenbush, S. W., \& Bryk, A. S. (2002). Hierarchical linear models. Applications and data analysis methods (2nd ed.). Thousand Oaks: Sage Publications.

Raudenbush, S. W., Bryk, A. S., \& Congdon, R. (2005). Hierarchical Linear Modelling, HLM (Version 6.01) [Computer Software]. Lincolnwood, IL: Scientific Software International.

Robinson, W. (1950). Ecological correlations and the behavior of individuals. American Sociological Review, 15, 351-375.

Salovey, P., Rothman, A. J., Detweiler, J. D., \& Steward, W. T. (2000). Emotional states and physical health. American Psychologist, 55, $110-121$.

Slavin, R. E. (1994). Using student team learning (4th ed.). Baltimore: Johns Hopkins University, Center for Research on Elementary and Middle Schools.

Spielberger, C. D. (1972). Anxiety as an emotional state. In C. D. Spielberger (Ed.), Anxiety. Current trends in theory and research, Vol. 1 (pp. 23-49). New York: Academic Press.

Titz, W. (2001). Emotionen von Studierenden in Lernsituationen. Explorative Analysen und Entwicklung von Selbstberichtskalen [Unversity students' emotions in learning situations. Analyses and development of self report scales]. Münster, Germany: Waxmann.

Turner, J., Midgley, C., Meyer, D., Gheen, M., Anderman, E., \& Kang, Y., et al. (2002). The classroom environment and students' reports of avoidance behaviors in mathematics: a multi method study. Journal of Educational Psychology, 94, 88-106.

Tymms, P. (April 2004). Now you see them, now you don't - compositional effects and level 1 reliability. Paper presented at the Annual Meeting of the American Educational Research Association (AERA), San Diego, CA.

Urdan, T. (2004). Using multiple methods to assess students' perceptions of classroom goal structures. European Psychologist, 9, $222-231$.

Van Damme, J. A. \& Opdendakker, M. C. (April 2004). Can school type be used as an explanation of the school composition? An answer form Flemish research. Paper presented at the Annual Meeting of the American Educational Research Association (AERA), San Diego, CA.

Von Saldern, M., \& Littig, K. A. (1987). Landauer Skalen zum Schulklima [The Landau scales for assessing school climate]. Weinheim, Germany: Beltz.

Weiner, B. (1986). An attributional theory of motivation and emotion. New York: Springer.

Weinstein, C. S. (1999). Reflections on best practices and promising programs: beyond assertive discipline. In H. J. Freiberg (Ed.), Beyond behaviourism: Changing the classroom management paradigm (pp. 147-163). Boston: Allyn \& Bacon.

Wigfield, A., \& Meece, J. L. (1988). Math anxiety in elementary and secondary school students. Journal of Educational Psychology, 80, $210-216$.

Willms, J. D. (1986). Social class segregation and its relationship to pupils' examination results in Scotland. American Sociological Review, 51, 224-241.

Zeidner, M. (1998). Test anxiety: The state of the art. New York: Plenum.

Zeidner, M., \& Schleyer, E. J. (1998). The Big Fish Little Pond Effect for academic self concept, test anxiety, and school grades in gifted chil dren. Contemporary Educational Psychology, 24, 305-329. 